\title{
Los indios de Jesús María y su lucha por la tierra, 1699-1910
}

\section{Jesús Gómez Serrano}

\begin{abstract}
Quizá la violencia que más afectó a los indios fue la que se hizo sentir sobre sus tierras de comunidad, porque éstas eran el cemento que daba cohesión y orden a toda la vida indigena. Sin las tierras de comunidad no se puede ni siquiera imaginar la célula básica de la comunidad indigena: el pueblo de indios... el pueblo de indios era la tierra: ella era el fundamento que mantenía a la comunidad y sobre ella reposaban la familia y el individuo. Por eso, mientras los pueblos conservaron la tierra, mantuvieron su integridad como pueblos, su cohesión social y hasta sus tradiciones y costumbres. En cambio. los puebios que perdieron sus tierras se desintegraron rápidamente y sus componentes fueron absorbidos por la hacienda o la ciudad europea dejando de ser indios. De ahi que esa lucha tenaz e insobornable que protagonizaron los indios en cada día de los tres siglos del régimen colonial, más que una lucha por la tierra, debe considerarse como una batalla por la supervivencia. Paradójicamente, esa lucha desigual y cotidiana por la tierra vino a ser, entre los cientos de factores disolventes que amenazaban la integridad de las comunidades. un factor positivo que mantuvo la cohesión social de los pueblos indigenas.
\end{abstract}

Enrique Florescano, Origen y desarrollo de los problemas agrarios de México. 1500-1821, México. Ediciones Era, 1976, p. 119-120.

$\mathbf{H}$ asta fechas recientes los historiadores profesionales habían prestado poco interés al problema indígena. Charles Gibson. T.G. Powell y otros, con sus investigaciones pioneras, han aportado sin duda una nueva luz al conocimiento de la realidad nacional. Como casi siempre, la verdad parece querer colocarse en un punto intermedio, equidistante en este caso entre la leyenda negra, que abusaba de las crónicas de horrores, $y$ las versiones hispanófilas. que negaban la violencia y querían ver en las instituciones coloniales tan sólo el elemento civilizador. En la región de Aguascalientes, cuatro comunidades indigenas fueron establecidas; la de Jesús Maria, fundada en 1699. es dueña de una historia singular. Su cercanía con la villa de Aguascalientes. los términos en los que recibieron su dotación primordial de tierras y su incesante crecimiento la obligaron a vivir en un estado de constante alarma. La biografía de este pueblo de indios está marciada por la defensa de sus recursos, la tierra y el agua, sobre los cuales giraba la posibilidad misma de que la comunidad subsistiera como tal. En su lucha incesante, el pueblo no salió siempre mal librado; en más de una ocasión se le hizo justicia, se prestó oídos a sus demandas. Esta circunstancia es importante porque nos permite entender el obstinado legalismo de los indios y porque desbarata la versión de un Estado (español o porfiriano) esencialmente opresivo e injusto, colocado siempre del lado del poderoso.

Reconstruir esta historia, desde una perspectiva que incluya la simpatía pero no anule la objetividad, es la intención de este articulo. ${ }^{1}$

Tengo una deuda de gratitud muy especial con el profesor Alejandro Topete del Valle. quien amablemente me facilitó varios documentos. Jean Meyer y Eugenia Meyer, además, me ayudaron con sus estimulantes comentarios. 


\section{La fundación del pueblo; su sentido y alcance}

El pueblo de indios de Jesús María fue apenas la tercera comunidad de este tipo que se estableció en la jurisdicción de la villa de Aguascalientes. Al parecer, el principal promotor del nuevo asentamiento fue el cacique Matías Saucedo y Moctezuma, que había estado negociando desde 1699 la obtención del sitio conocido como Jonacatique, ubicado unas cuatro leguas al norponiente de la villa de Aguascalientes y perteneciente al propietario del mayorazgo de Ciénega de Mata aunque no vinculado a él. ${ }^{2}$ El capitán José Rincón Gallardo, en ese momento titular del vínculo, aceptó ceder un sitio de ganado mayor y cuatro caballerías (1927.2 hectáreas) con la precisa condición de "recibir a cambio ciertos servicios en sus tierras de labor". La donación fue escriturada en la ciudad de Guadalajara, ante las autoridades de la Real Audiencia, el 24 de julio de 1699. ${ }^{3}$

Así, debidamente legalizada la posesión del terreno en que habría de fundarse el nuevo asentamiento, el cacique Saucedo y Moctezuma y sus compañeros encaminaron sus esfuerzos a obtener de la autoridad civil el permiso para establecerse en la quieta y pacífica posesión de sus tierras, trazando el perfil del nuevo pueblo y repartiendo las labores. Por fin, el 23 de diciembre de 1700 el doctor don Alonzo de Cevallos Villa Gutiérrez, funcionario de la Real Audiencia de la Nueva Galicia, y don Francisco Domínguez de Riezo, concedian la ansiada licencia de fundación:

... En cuya conformidad y en atención a lo dispuesto por la real cédula preinserta y leyes citadas y las demás que hablan en razón de las nuevas poblaciones, en nombre de su majestad y sin perjuicio de su real derecho, doy y concedo licencia a los dichos Juan Rodríguez, Domingo de Lima. Miguel Suárez y demás consortes ranchados en el puesto del Charco Azul, para que en el dicho sitio del Mezquital o Juanacatique puedan fincar el referido pueblo que pretenden, para cuyo efecto mando que el Alcalde Mayor de la villa de Aguascalientes pase personalmente a dicho sitio y haga formar la planta de la Iglesia y casas reales en la plaza principal de dicho pueblo, y las casas y calles de él... haciendo repartan entre $s i$ dichos naturales las tierras de dicho ejido conforme a la constitución de los pobladores... ${ }^{4}$

Un poco después, el 29 de noviembre de 1701, el licenciado don Diego de Parga y Galloso, abogado de la Real Audiencia de la Nueva Galicia, regidor decano de la ciudad de Zacatecas y Alcalde Mayor y de la Santa Hermandad en la villa de Aguascalientes y su jurisdicción, procedió a confirmar el derecho de los indios a fundar el nuevo pueblo y a usufructuar los terrenos que les habian sido donados. El auto de fundación, que contiene indicaciones con un alto valor testimonial, dice:

Ante mí Salvador Delgado Cervantes, escribano público y de cabildo, en el sitio nombrado Juanacatique. jurisdicción de la villa de Aguascalientes. que está como a dos leguas de ella poco más o menos, en primero de di-

2 Alejandro Topete del Valle. Aguascalientes, guía para visitar la ciudad y el estado. (tercera edición propiedad del autor). Aguascalientes, 1973, p. 21

3 Beatriz Rojas, La destrucción de la hacienda en Aguascalientes, 1910-1931. El Colegio de Michoacán, 1980. p. 15.

4 Un testimonio parcial del auto en Archivo General del Estado de Aguascalientes (en los sucesivo AGEA). Ramo del Poder Judicial, Sección de Asuntos Civiles (en lo sucesivo PJ [Civil]. 1883,p. 17 
ciembre de 1701, habiendo venido a efecto de asentar la población que se ordena por el despacho antecedente parecieron D. Juan Rodríguez de Tapia, D. Miguel Hernández y otros naturales y dijeron que por si y en nombre de Diego Flores, Marcos de Saucedo y otros indios que nombraron, que por estar ocupados en el puesto de los Pilotos no comparecían, pedian se les diese posesión de dicho puesto para fundar un pueblo, a quien ponían por nombre Jesús María de los Dolores, que visto por su merced el señor Alcalde Mayor, mandó reconocer la parte donde se habia de formar la planta del pueblo, conforme a lo dispuesto por la leyes reales, en la parte donde dichos naturales tenían puesta una campana que señalara el lugar donde había de ser la iglesia, se halla ser el más conveniente, asi por ser levantado, llano y descubierto el sitio, como porque el agua que les había de servir entra por sí sola por todo él, y pueden aprovecharle para fábrica de sus casas y huertas, y dejando asentado el sitio para la iglesia donde habían elegido se echaran las medidas para formar la plaza, que por ser pocos los naturales se les dio de largo trescientos pasos y de ancho doscientos, advirtiéndoles que habian de cuadrar como estaba asignada la dicha plaza, por un lado la iglesia, por el otro las casas reales y por los demás fabricasen sus casas, para que estando juntos, cercanos y vecinos unos de otros, se pudieren socorrer $y$ acudir en lo que necesitaren. y en cada esquina de dicha plaza se formaran dos calles, para que siguiesen sus legítimas y extendiesen su población según el orden y regla que se les dio.

Después de lo cual cogió su merced por la mano al dicho D. Juan Rodríguez de Tapia y a los demás naturales que se hallaron presentes y les metió en posesión de dicho sitio en nombre de su majestad, y ellos, en señal de aprehenderla, hicieron actos de posesión arrancando yerbas, tirando piedras, manoseando el agua y repicando su campana. En cuya posesión su merced dijo les amparaba y amparó; y en cuanto a los ejidos de dicho pueblo observen la distancia de dicho sitio y caballerías de tierra que se les donó, y si sobre esto. o repartimiento de su suerte y solares hubiere algún inconveniente, ocurran a su merced por la providencia necesaria. $^{5}$

La fundación de este pueblo, que aparece llena de vitalidad en los documentos transcritos, es motivo de varias reflexiones. En primer lugar, parece clara la relación entre el nuevo asentamiento y la necesidad de mano de obra por parte de los terratenientes locales. Los trabajadores esclavos eran pocos $y$ caros, las encomiendas habían sido restringidas desde el siglo XVI, los repartimientos de indios no podían prosperar dada la escasa cantidad de pueblos existentes en la zona y, finalmente, el peonaje por deudas y la aparcería eran instituciones apenas nacientes, incapaces de satisfacer los requerimientos de trabajo de las pujantes haciendas agrícolas y ganaderas comarcanas. De esta manera, el mecanismo ideado por don José Rincón Gallardo, con creces el principal latifundista en la zona, consistente en ceder parte de sus tierras a un nuevo pueblo de indios a cambio de servicios en trabajo, parece muy afortunado. Don José perdía unas pocas caballerías de tierra, que escaso peso tenían en el contexto de sus numerosas propiedades, pero ganaba treinta y dos pares de brazos trabajadores, indispensables en todas las faenas del campo. ${ }^{6}$

- Ibid.... En este mismo documento se puede encontrar una lista con los nombres de los treinta y dos "primeros fundadores" del pueblo.

- La apropiación del trabajo indígena por parte de los españoles revistió múltiples modalidades: encomienda, repartimiento. utilización de reos convictos. contratación privada en los obra. 
Los indígenas se quejaron después, en repetidas ocasiones, de que sus obligaciones para con los Rincón Gallardo eran excesivamente gravosas. En octubre de 1800. por ejemplo, cuando se pedian nuevas tierras, se señalaba que la donación de 1699 se había hecho

bajo condiciones serviles, sujetándolos en términos tales que lo que parece donación graciosa no es más que inicuo medio de explotación, $v$ tan gravoso. que privándolos de la libertad con que pudieran activarlo. los obliga a destinarse en el tiempo crítico de las aguas, y en los otros a propósito para la siembra de las semillas de primera necesidad, a desatender sus sementeras, abandonándolas enteramente, y a emplearse en las haciendas del vínculo, en los trabajos todos de ellas mismas. ${ }^{7}$

Los indigenas llegaban a la conclusión obvia de que "semejante sistema y género de vida subyugada es a la verdad insoportable". Es probable, sin embargo, que estos lamentos exageren un poco la realidad de las cosas. Hay que tener en cuenta que a los de Jesús María les interesaba mucho impresionar a las autoridades. pues de ello dependía en buena medida que se les concediera la gracia demandada. Además, según la versión de funcionarios de la Intendencia de Guadalajara, en los documentos exhibidos por los indios "no consta que la donación se les hiciera por el capitán Gallardo bajo de condiciones algunas, ni mucho menos haberse obligado por ella a ninguna contribución ni servicios gravosos". ${ }^{8}$

Por otro lado, conviene recordar que la fundación del pueblo de Jesús María no respondía al reto representado por la llamada "guerra chichimeca". 9 Para 1700, la zona de Aguascalientes estaba copletamente pacificada; además, los escasos indios que merodeaban en la región habían sido exterminados o incorporados a los núcleos de población hispanos. De todas formas, el asentamiento del nuevo grupo de "naturales" (cuyo origen étnico nos es desconocido, aunque muy probablemente se trataba de mexicas) ${ }^{10}$ viene a ser una especie de eslabón en el proceso de integración de los territorios conquistados. No bastaba pacificar una región, diezmar su población nativa y dilapidar los recursos más inmediatamente obtenibles; era necesario, además, auspiciar el desarrollo agrícola y ganadero, fomentar la integración de toda una red de comunicaciones, activar el comercio y fortalecer el peso económico y político de los nuevos núcleos de población. En todas estas tareas, más propias de una empresa de colonización que de conquista, la disposición de mano de obra resultaba vital. En la región de Aguascalientes. donde los esclavos eran caros y escasos y los asentamientos prehispánicos nulos, la fundación de un pueblo como el de Jesús María atacaba directamente el problema. Y no deja de llamar la atención el que fuera un particular el primero en auspiciar, a través de una donación de terrenos, la formación del

jes o fincas, etcétera. El arreglo con los indios de Jesús Maria ciertamente fue especial. (Véase sobre este particular: Charles Gibson, Los aztecas bajo el dominio español. México. Siglo XXI. 1967, capítulo 9: "El Trabajo", p. 225-262).

7 Me apoyo en el legajo titulado "Copia certificada de los documentos que en papel sellado del sello tercero pertenecientes a los años de 1854 y 1855 y en cincuenta y una fojas útiles corresponde a la Sierra Fría propiedad de los indigenas de Jesús Maria. Aguascalientes, enero de 1891 ". (Copia mecanoscrita del lagajo en poder del profesor Alejandro Topete del Valle.p. 2-4.) En lo sucesivo, para aludir a este legajo, abreviaré Documento ATV

${ }^{8}$ lbid., p. 6.

9 Sobre el particular véase el trabajo de Phillip W. Powell, La Guerra Chichimeca, México. Fondo de Cultura Económica, 1977

10 Esta hipótesis es del profesor Topete del Valie, quien basa su presunción en el apellido Moctezuma del cacique fundador. 
nuevo pueblo; la Corona, que era la instancia que normalmente acometía estas empresas, se limitó a secundar la iniciativa, concediendo el permiso de fundación solicitado y dando a los indígenas la posesión legal de sus tierras.

\section{El pueblo: recursos y población}

Las tierras mercedadas originalmente a los indios jesusmarianos fueron utilizadas en parte en la erección del pueblo mismo, con su plaza, sus edificios públicos y su caserío, y en parte en forma de pequeños predios rústicos familiares, y en los que se levantaban anualmente regulares cosechas de maíz y frijol. Conforme la población creció. las parcelas fueron subdividiéndose hasta llegar a constituir minúsculos reductos cuyos productos no eran suficientes para la manutención familiar. ${ }^{11}$ En vista de esta situación, los naturales de Jesús María presentaron un escrito ante las autoridades reales, fechado el 20 de octubre de 1800, en el que denunciaban como realengas unas tierras situadas al poniente de la hacienda de Pabellón. en la parte alta de la Sierra Fría. y de las cuales solicitaban la posesión de tres sitios de ganado mayor, uno como fundo legal del pueblo y los otros dos vendidos. En su escrito, los indígenas expresaban que "el número de familias es crecidísimo", que los tributos pagados anualmente sumaban una buena cantidad, ${ }^{12}$ que el pueblo "no tiene el fundo debido" y que por todo ello su petición merecía ser escuchada. ${ }^{13}$ Posteriormente, en un escrito fechado el 13 de noviembre de 1800 . los indios aclaraban que su única pretensión era lograr una extensión mediana en tierras "que sean capaces al mismo tiempo que útiles, para que en ellas y con sus pastos puedan cómodamente mantenerse los ganados, así comunes como particulares de los indios, y con la labranza éstos adquieran su necesaria manutención y subsistencia..."14

El denuncio fue admitido y se confirió al agrimensor Francisco Ramírez Morales la comisión de, verificar las "diligencias de medidas" en presencia de los dueños de la hacienda de Pabellón y de los naturales de San José de la Isla, quienes alegaban haber denunciado las tierras en cuestión con anterioridad a los de Jesús María. ${ }^{15}$ Con el fin de verificar si las pretensiones de los de San José de la Isla tenían fundamento, el agrimensor Ramírez Morales llevó a cabo una vista de ojos el 7 de diciembre de 1801, y en compañia de los diversos interesados recorrió la serranía. Dos días después, teniendo en sus manos los títulos y el mapa presentados por los dueños de Pabellón, el agrimensor verificó las medidas de las tierras denunciadas por los indígenas jesusmarianos. Concluidas las diligencias en los primeros días de enero de 1802, se les hizo entrega a los indios de tres sitios de ganado mayor. Los terrenos, según la caracterización que de ellos hizo el propio agrimensor,

están en lo más incógnito de las barrancas, en situación montuosa, sin tierras útiles para sembrados (características que) le traen justamente el renombre de inútiles, a lo que se agrega el sumo frío que en todo tiempo

1 Tanto por su carácter campesino como por su relación con las haciendas circunvecinas, el caso de Jesús María es muy semejante al de todas las comunidades indígenas asentadas en el centro de México. Véase: T. G. Powell, El /iberalismo y el campesinado en el centro de México (1850-1876). México. SepSetentas, núm. 122, 1974, capítulo 2.

12329.3 pesos anuales, según un informe oficial. (Documento ATV, p. 4).

13 Copia del escrito en Documento ATV. p. 4-6.

14 Copia del escrito en ibid.

15 Este dato y algunos otros se encuentran en un expediente girado por la Oficina Jurídica del Departamento Agrario en mayo de 1946. Una copia de dicho expediente obra en poder del AGEA, a cuyo director agradezco el habérmela facilitado. 
se experimenta en aquella inaccesible serranía, que no permite conservar milpas, ni hortalizas, ni otras cosas que son los ordinarios arbitrios de los indios para su subsistencia, de manera que sólo para fábrica de carbón. corte de leña y madera son útiles aquellos inhabitables montes... En ellos no hay aguas perennes si no es las del Arco del Toro, que por estar una profunda barranca al lado de peñasqueras intransitables, la dejan únicamente para aguajes de animales. Sus pastos son serranos, cuya cualidad es siempre insustanciosa, que no sostiene a los ganados y demás crias sino en el tiempo de las aguas. ${ }^{16}$

De cualquier forma, estos tres sitios de ganado mayor (5 268 hectáreas) se sumaron al exiguo patrimonio del pueblo, aligerando un poco los rigores de su existencia. Asi, antes de la guerra de independencia los indios de Jesús María detentaban la posesión de dos terrenos, cuya extensión conjunta sumaba 7195.2 hectáreas. Esta cifra no habría de sufrir alteraciones mayores sino hasta la década de los años veinte del presente siglo, cuando se llevó a cabo la dotación de ejidos.

En cuanto a su población, tenemos que el pueblo de Jesús María estuvo en un principio habitado tan sólo por las treinta y dos familias de los fundadores, esto es, por 150 personas más o menos. En 1794, según la información suministrada por el subdelegado Herrera y Leyva, el caserío estaba muy extendido y su población alcanzaba las 1098 almas. De este total, el 66.02 por ciento eran varones y el 33.98 restante eran mujeres. ${ }^{17}$ En 1837, a guiarnos por los datos del llamado Primer Cuadro Estadístico del Departamento de Aguascalientes, Jesús María estaba habitado por 1083 hombres y 750 mujeres, que hacian un total de 1843 personas. $^{18}$ En 1887, según los datos del gobernador Gómez Hornedo, la población de Jesús Maria era de "aproximadamente" 2500 personas. ${ }^{19}$ Los resultados del Censo de 1900. por su parte, le dieron al pueblo un total de 2764 habitantes, integrado por mitades casi exactas de hombres y mujeres. ${ }^{20}$ Diez años después. se registraba un brusco descenso demográfico, del orden del 27.42 por ciento, que tenía abatida la población hasta 2006 habitantes. ${ }^{21}$ En 1921, por último, se encontró con que la revolución había hecho estragos en Jesús María, disminuyendo el número de pobladores hasta 1358 , menos que los contabilizados cien años antes. ${ }^{22}$

La subsistencia de los indígenas giraba en torno al cultivo de sus parcelas - de donde obtenían un poco de maíz-, al cuidado de sus pequeños huertos y a la extracción de carbón y leña en la Sierra Fría, que luego vendían en la villa de Aguascalientes y a veces en puntos tan alejados como la ciudad de Zacatecas. Además, claro está, los de Jesús María tenían que prestar numerosos servicios en las tierras de labor de los Rincón Gallardo. Diversos testimonios coinciden en señalar que los medios de existencia de los indígenas eran sumamente precarios. En su Descripción (1794). Herrera y Leyva señalaba

16 Esta descripción en Documento ATV. p. 24-25.

17 Pedro Herrera y Leyva, "Descripción de la subdelegación de Aguascalientes, 1794". en Agustín R. González, Historia de Aguascalientes. segunda edición. Aguascalientes, 1974. p. $41-47$

18 Joaquín de Avila, Francisco Romo de Vivar. Manuel Alejandro Calera y Francisco Semería. "Noticias Estadísticas del Departamento de Aguascalientes" correspondientes al año de 1837. Primer Cuadro Estadistico del Departamento de Aguascalientes, en Boletin de la Sociedad de Geografia y Estadística, vol. 1. números 8 y 9 . correspondientes a enero y febrero de 1850.

19 Francisco G. Hornedo. Memoria Administrativa, 1883-1887, Anexo 104.

20 Censo General de Población. 1900

21 Censo General de Población. 1910.

22 Censo General de Población. 1921. 
que los naturales de Jesús María "se mantienen de una corta labor de maíz y de conducir carbón y leña para el abasto de la villa". ${ }^{23}$ En un documento ligeramente posterior (1800), los comuneros se quejaban de que "lejos de destinarse a la agricultura y labranza... sólo tienen por oficio la extracción de las maderas ( $y$ ) la fabricación con esta misma del carbón y de la leña". ${ }^{24}$ Por último, en un texto que data de 1854 y en el que los indígenas hacian una vívida recapitulación de sus problemas, se hacia notar que las tierras del sitio donde se hallaba fundado el pueblo "son muy delgadas y estériles, ocupadas en su totalidad en la sementera, que en la mayoría se pierde por escasez de las aguas; entonces aquellos indígenas suplen sus necesidades con su leña y carbones que sacan de los terrenos que tienen en la Sierra Fría". Se señalaba también la falta de praderas "donde puedan pastar sus muebles, causándose diariamente unos con otros graves daños y perjuicios en sus sembrados". 25 La Noticia Estadística de 1839 indica que de las 370 familias que habitaban el poblado, 39 eran de artesanos. El señalamiento es por lo menos equívoco. pues no hay ningún otro testimonio que lo avale. Por el contrario, en muchos informes se dice explícitamente que el pueblo había carecido siempre de pequeños obrajes de textiles, curtidurías de pieles, talleres de carpintería o cualquier otro tipo de industria artesanal que significara una fuente adicional de ocupación e ingresos. ${ }^{26}$ De esta manera, deprovistos de un recurso que era tradicional en muchas comunidades indígenas del centro del país, la economía de los jesusmarianos giraba exclusivamente en torno a los productos de la tierra. ${ }^{27}$

\section{La defensa de la tierra.}

Según los archivos que hemos consultado, la primera ocasión en la que los indios se vieron obligados a defender sus tierras tuvo lugar entre los años 1840 y 1857 . Fue un pleito largo y difícil que finalmente pudieron ganar. EI origen de las disputas se remonta a los primeros meses de 1840 , cuando ef ayuntamiento de Aguascalientes dispuso se reconocieran algunos terrenos baldíos en la Sierra Fría, al parecer con el objeto de lograr un provecho derecto. Por su parte, los indígenas de San José de la Isla (Zacatecas) habían solicitado que se tiraran algunas medidas y se repartieran ciertas tierras colindantes entre las suyas y las de los jesusmarianos. Los gobiernos departamentales de Aguascalientes y Zacatecas llegaron al acuerdo de nombrar peritos agrimensores "para que trazaran los límites dentro de los cuales cada

23 Pedro Herrera y Leyva, op. cit.

24 Se trata del escrito en el que se solicitaban tierras $(20-X-1800)$. al que ya se hizo alusión en la nota 13 .

25 Es un escrito firmado por Esteban Marcial, "Comisario Municipal del pueblo de Jesús María" y fechado el 12 de octubre de $\$$ 854, al que aludiremos en forma más amplia páginas adelante. (Copia en Documento ATV, p. 67.)

26 Por ejemplo, un informe de 1922 que se conserva en AGEA-Ramo Secretaría de Gobierno (en lo sucesivo SG). 1922, p. 124,250

27 Esta precariedad no era privativa de los indigenas de Jesús María. Los nativos de San José de Gracia también se quejaron reiteradamente de la pobreza de sus medios de vida. En un escrito fechado en enero de 1855 exponía que su pueblo, "esta reunión de más de tres mil habitantes arrojados por el todopoderoso en el centro de las montañas, fuera de la línea de las poblaciones comerciales, separado de los caminos públicos, sin relaciones con los pueblos civilizados, vive aislado a su propio destino, sin más elementos de vida que el ejercicio de la maderería y de la ieña, que es el único giro de nosotros sus habitantes... No tenemos un palmo de tierra en que dedicarnos a la agricultura o a la labranza, ni hay industria, comercio o artes que pudieran darnos animación... Vivimos mezquinamente..." (Copia de esta carta en Documento ATV. p. 88-89.) 
pueblo debía de contenerse" y "para que no se perjudicaran con aquel reconocimiento". ${ }^{28}$

El gobierno de Zacatecas vio en este asunto la ocasión de restar fuerzas a su homólogo aguascalentense, que recién había obtenido su independencia. Para ello juzgó oportuno despertar en los indígenas de San José de Gracia, habitantes de la parte más recóndita de la Sierra y secularmente pobres, el deseo de ocupar nuevos terrenos. Se contrataron los servicios de un perito bien advertido de la indole del negocio que se traía entre manos y se concluyó, claro está, que entre los predios de San José de la Isla y Jesús María había un baldío con una extensión de tres sitios de ganado mayor. Así, el 24 de diciembre de 1840 representantes del gobierno zacatecano confirieron a los de San José de Gracia "fracción y título" del terreno supuestamente realengo. pero que en realidad pertenecía a los de Jesús María. Se hizo constar que las tierras serían disfrutadas en comunidad por los de San José de Gracia, "en tanto el supremo gobierno dispone se repartan entre las propias familias con arreglo a las leyes en la materia". ${ }^{29}$

Los indios jesusmarianos reaccionaron de inmediato, acudiendo ante el notario Isidro Arteaga y dando testimonio de que habían sido despojados "de un terreno que ocupaban en la Sierra Fría". En vista de esta situación. conferían un poder amplio a Julián Santoyo "para que promueva y siga este negocio y los demás que se ofrezcan al común del pueblo... (y) para que entable desde luego el juicio sumarísimo de despojo y los demás que le parezca conveniente entablar..." ${ }^{30}$ Santoyo presentó un escrito ante el juez segundo de letras de Aguascalientes en el que declaraba que el pueblo de San José de Gracia había despojado a sus representados de un terreno nombrado Ciénega de Cebolletas y de una parte de la Barranca del Toro, puntos ambos situados en la Sierra Fría. Con el fin de acreditar los derechos que el pueblo de Jesús María tenía sobre esos terrenos. Santoyo presentó, con fecha 20 de noviembre de 1841, la correspondiente información testimonial. El juez, por medio de una sentencia firmada el 22 de noviembre de 1841 , decretó que "siendo probados los extremos legales de posesión y despojo, única circunstancia que previene el derecho para que los despojados se constituyan a la posesión, pasará el presente juez a poner en ella a los indígenas de Jesús María, señalando para ello el día de mañana, citándose a los colindantes para dicho efecto". 31

Asi se hizo, aunque los de San José de Gracia no quedaron conformes y pidieron que se practicara una medición de los terrenos disputados, con objeto de saber si estaban incluidos en los límites de los tres sitios pertenecientes a Jesús María. El deslinde fue autorizado y para su ejecución se comisionó al perito agrimensor Francisco Ignacio Romo de Vivar, quien inició sus trabajos el 14 de enero de 1843. Los resultados de estas diligencias favorecieron nuevamente al pueblo de Jesús María, pero los de San José de Gracia se negaron a acatarlas. El pleito. después, se enmarañó con el problema de la independencia política de Aguascalientes. En 1847, cuando las autoridades zacatecanas acababan de lograr la reintegración a su patrimonio territorial del antiguo Departamento de Aguascalientes, se empeñaron en que los terrenos disputados fueran declarados baldíos y luego vendidos al mejor postor. Para ello se valieron nuevamente de la angustiosa situación de los de

${ }^{28}$ Un testimonio de todo esto en Documento ATV, p. 56

29 Ibid.

30 Archivo Histórico del Estado de Aguascalientes, Fondo de Protocolos Notariales len lo sucesivo AHEA-FPN), Not. Isidro Arteaga, 1840-1841, s.n, s.f. El poder está autorizado por 44 firmas y por el Juez de Paz. Juan de Luna, "a nombre de los que no saben firmar".

31 Copia de la resolución del juez en Documento ATV, p. 46. 
San José de Gracia, a quienes fueron confiados en calidad de depósito los tres sitios peleados. Con ello se amenazaba a los de Jesús María con hundirlos en "una espantosa ruina... vendiéndoles sus tierras, de donde sacan leña y carbón, recursos miserables de su subsistencia". ${ }^{32}$

En esta situación de indefinición estuvieron las cosas durante algunos años, hasta que en 1854, habiendo conquistado Aguascalientes en forma definitiva su independencia política, pudo actuar con manos libres y dar la razón a sus antiguos aliados. los indios de Jesús María. Estos últimos se habían dirigido, a través del comisario municipal del pueblo y de su apoderado legal, al gobernador aguascalentense, exponiéndole detalladamente el problema y pidiéndole:

se digne decretar que sin más forma de juicio aquellos indígenas sean restituidos de tres sitios de ganado mayor... y mandar que ambos comisarios de los pueblos de San José de Gracia y Jesús María, poniéndose de acuerdo, cuiden de que los indígenas de aquellos pueblos se contengan en el límite que ya se les tiene marcado... ${ }^{33}$

El expediente fue turnado al licenciado Francisco Borja Jayme. "para que se sirva consultar sobre la justicia o injusticia del pedido que hacen los indigenas de Jesús María". El abógado, aunque reconoció que el interdicto de restitución no había sido tramitado por la vía legal debida, falló en favor de los de Jesús María. ${ }^{34}$ En tal virtud se expidió un decreto con fecha 6 de enero de 1855, en el que se ordenaba al subprefecto de Rincón de Romos que pusiera en posesión de los terrenos serranos a los indígenas jesusmarianos. De nuevo manifestaron su descontento los de San José de Gracia, pero de nuevo el gobierno del estado les hizo saber que no era posible acceder a sus peticiones. En opinión del gobierno aguascalentense, los de San José de Gracia no tenían ningún derecho sobre las tierras en disputa y, paralelamente. los de Jesús María "han acreditado con documentos legales y probado hasta la saciedad ser suya la sierra..." 35

El corolario de esta lucha tuvo lugar el 26 de agosto de 1856, cuando el gobernador Jesús Terán decretó que "los terrenos de la Sierra Fria pertenecientes al pueblo de Jesús María se repartirán, según con anterioridad está determinado, entre las familias que forman dicho pueblo". Las fracciones serían sorteadas y si hubiera sobrantes "se darán a los que los pidan, aunque no sean del pueblo de Jesús María, siempre que no sean dueños ya de otras fracciones". Una porción del terreno se separaría "para formar una población. con el nombre que la junta municipal acuerde"; en este nuevo poblado podrían avecindarse "las personas que lo pidan, sean de donde fueren". Los vecinos tenían obligación de cercar sus solares y de construir en ellos por lo menos una habitación. Por último, se prevenia que "tan luego como haya veinte familias en la población, la jefatura de Rincón dispondrá que se construya una cárcel, escuela y una casa municipal". ${ }^{36}$

32 Toda esta relación en el extenso escrito de Esteban Marcial fechado el 12 de octubre de 1854 y ya citado en la nota 25. (Copia del escrito en Documento ATV, p. 58-73.)

33 Véase el escrito de Esteban Marcial ya citado.

34 El fallo de Borja Jayme en Documento ATV, p. 82-83.

35 Este fallo definitivo fue fechado el 20 de enero de 1855 . Copia en Documento ATV, $p$ 90-91

36 El decreto fue reproducido en el periódico capitalino El Omnibus, 16-1X-1856. (Copia del decreto nos fue amablemente proporcionada por el profesor Alejandro Topete el Valle). 
Parece obvio que la intención de este decreto era múltiple. En primer lugar, muy a tono con la ley de desamortización de bienes de las corporaciones que recién acababa de expedirse, el gobernador Terán disponía la conversión de terrenos comunales en pequeños predios particulares. De esta manera, además, los indígenas jesusmarianós se consolidaban en la posesión y disfrute de las tierras de la Sierra Fría, también pretendidas por los habitantes de San José de Gracia. Por otra parte. Terán procuraba promover la formación de un nuevo asiento poblacional, el cual, no por azar, quedaría ubicado en una de las regiones más aisladas y de más difícil acceso de todo el estado. Sin embargo, al margen de sus intenciones, el decreto no pudo surtir todos sus efectos. Desde luego, la formación de un nuevo poblado se quedó en proyecto. Además, el deslinde y reparto de tierras entre las familias indígenas se vio seriamente obstruido, tanto por la precaria estabilidad del gobierno liberal encabezado por Terán como por la pugna entre los dos pueblos interesados en los terrenos. De hecho, aunque con el paso del tiempo esta parte del decreto gubernamental se hizo realidad. no se podría señalar con precisión qué tanto influyó en ello la voluntad del ejecutivo.

Durante el último cuarto del siglo XIX, aunque por otros conductos $y$ con objetivos diferentes, la lucha proseguía. Ahora no se trataba de defender los terrenos de la sierra, sino los de la parte de abajo. los que constituyeron originalmente el asiento de la comunidad. El 13 de febrero de 1875, ante la fe pública de un escribano, 543 varones "mayores de edad e indígenas del pueblo de Jesús María" ${ }^{37}$ declararon que algunas de sus tierras estaban siendo trabajadas por gente extraña y que era necesario reintegrarlas al patrimonio comunal. En consecuencia, los indios otorgaban un poder al licenciado Manuel Collado para que:

en representación de los derechos que nos asisten en común y como particulares, con nuestro carácter de indígenas del pueblo de Jesús María haga y practique las diligencias que a continuación se expresan: Primera: para que descubra y aclare los terrenos que pertenecen al repetido pueblo de Jesús María, procedentes de un sitio y cuatro caballerías de que hizo donación el señor don José Rincón Gallardo... Segunda: para que entable los juicios que correspondan con el objeto de reclamar dichos terrenos hasta recuperarlos y tomar posesión de ellos, practicando cuantas diligencias sean conducentes... Cuarta: para que perciba, demande y cobre las cantidades que se deban a los mismos indígenas del pueblo de Jesús María en razón del arrendamiento de los terrenos que se les tengan usurpados, las costas, daños y perjuicios que se les hayan originado a consecuencia de esa usurpación y todos los demás a que haya lugar... ${ }^{38}$

El licenciado Collado, según parece, mostró poco entusiasmo en el cumplimiento de las diligencias que le fueron encomendadas. En mayo de 1878 , tres años después de haberlo facultado, los indígenas se quejaban de que el abogado no había hecho caso de su asunto "por hallarse ausente", y como se ignoraba cuándo regresaría, "a fin de que esta circunstancia no les perjudique, han resuelto revocarle el expresado poder". A cambio, revestían

37 Estas 543 personas seguramente constituían el cien por ciento de los jefes de familia, pues la población total de Jesús María era, en 1887, de "cerca de 2500 habitantes". (Véase la nota 19.)

38 AGEA-Ramo de Protocolos Notariales (en aldelante PN). Not. Candelario Medina. 1875. p. $17,30-34$ 
de amplias facultades a José María Borjas, "indígena del repetido pueblo de Jesús Maria", para que practicara diligencias idénticas a las que se habian encomendado a Collado. ${ }^{39}$ Hasta donde podemos ver. Borjas era un vecino influyente y respetado, pues no era ésta la primera ocasión en la que los comuneros le confiaban sus asuntos. Sin embargo, pese a que Borjas estaba personalmente inmiscuido en el problema, sus empeños no prosperaron. Así, en mayo de 1882. Ios indígenas declaraban que "han deliberado revocar dicha procuración... (y) conferir su poder general y bastante al c. Domingo Cadena, vecino de Mechoacanejo..." Las tareas encomendadas a Cadena eran las que originalmente habían encargado al licenciado Collado y que luego traspasaron a José María Borjas: la delimitación exacta de los terrenos que les habían sido donados por José Rincón Gallardo y su reincorporación al patrimonio de la comunidad. ${ }^{40}$

Esta apretada sucesión de poderes y el hecho mismo de haber encargado tareas idénticas a tres personajes distintos, son circunstancias muy reveladoras del poco éxito que acompañaba las gestiones legales emprendidas por el pueblo. Tal parece que a su lucha por la tierra, a sus problemas de límites y a sus carencias en materia de obrajes e industrias, hubiera que agregar la carga inútil de leguleyos tramposos, coludidos o empantanados en los laberintos de la burocracia. Hay que imaginar la angustia y el coraje de esta gente sencilla y pobre, en su mayor parte analfabeta, al ver que la confianza depositada en la gente "de razón" era impunemente burlada. Hay que imaginar su perplejidad al escuchar la explicación de la infinidad de trámites legales que había que hacer para que su queja ltegara a los oídos del poder. Hay que imaginar su desesperación al sentirse atrapada e indefensa en el laberinto kafkiano de las audiencias, la firma de nuevos papeles y las promesas de atención nunca satisfechas. Hay que ver a los comuneros, esgrimiendo como única defensa el argumento roído de ciertos títulos de propiedad, bandera y prueba de la legitimidad de sus pretensiones, vapuleados por el más modesto de los funcionarios, ninguneados en cada bandazo del poder.

\section{La comunidad se defiende de sí misma}

La comunidad de indios de Jesús María tuvo que hacer frente no sólo a amenazas provenientes del exterior. A veces, las intentonas de abuso tenian su origen en el seno mismo de la comunidad, en la que también se alimentaban individualismos y rencillas. En 1883, por ejemplo algunos indios, animados por la ley de terrenos baldíos recientemente decretada, pensaron que podían hacer un gran negocio a costillas del principal bien comunal. El trámite era sencillo: declarar "baldio" un terreno ( $y$ el término era tan vago y la legislación tan complaciente que todo parecía radicar en el modo en que se planteara el asuntol, esperar la verificación de la autoridad correspondiente. pagar una cantidad ridícula y recibir, finalmente, un título de propiedad autorizado por el gobierno federal, es decir, irrebatible. En Jesús María no cabía duda acerca de cuáles eran los terrenos propios de la comunidad; sin embargo. los títulos se prestaban a ciertas dudas, la tradición oral y la conciencia colectiva poco peso legal tenían $y$. según parece, los papeles en los que constaban la dotación original y los autos de fundación del pueblo habían sido extraviados desde los años de la guerra de Independencia.

Hecha la declaración por los ambiciosos, el pueblo, como un solo hombre.

39 AGEA-PN, Not. Tranquilino Mercado, 1878, p. 31, 40-42.

40 AGEA-PN, Not. Tranquilino Mercado, 1882, p. 30, 33-34. 
tomó una serie de enérgicas medidas legales. El 5 de junio de 1883, más de 350 comuneros dirigieron un escrito al presidente municipal jesusmariano "en contra de los individuos Benito de Luna, Martín Hernández, José María Demetrio e Isidoro Saldaña, acusándolos de los delitos de conspiración y estafa" ${ }^{41}$ El munícipe aprehendió a los acusados y. junto con el escrito de acusación, los trasladó a la ciudad de Aguascalientes, donde quedaron bajo la custodia del juez de letras del ramo criminal. La comunidad creyó "que con este escarmiento se paralizarían los graves males de que nos quejábamos". Sin embargo, muy pocos días después se declaraba que:

con profundo pesar vemos introducido entre nosotros los indígenas el cisma que una fatalidad ha traído por unos cuantos descarriados indígenas hermanos nuestros, que sirviendo de instrumento no sabemos a qué perversas miras, para quererse apropiar las propiedades de los demás indígenas.

El número de los acusados había crecido, pues 24 comuneros se encargaron de proseguir el negocio iniciado por los encarcelados. Todos ellos habían llevado al agrimensor Jesús Aguirre y Fierro "para que les mida medio sitio de ganado" mayor del sitio en que se haya fundado este pueblo, para que se fraccione, según se platica, entre ellos y los demás indígenas que representan". ${ }^{42}$

Estos hechos lastimaron en lo más profundo los sentimientos de la comunidad. Ahora, los de Jesús María solicitaron la intervención del gobernador. En un escrito que le dirigieron el 22 de junio de 1883 imploraban:

el castigo de estos malos hermanos que ponen en el mayor conflicto a nuestras familias, nuestro humilde porvenir con que buscamos su subsistencia, y que con semejantes atentados han turbado el orden y paz pública de este lugar... Pedimos el ejemplar castigo de estos indígenas que nos han causado las más graves ofensas, introduciéndose en medir nuestras propiedades, destruyendo nuestras sementeras y árboles por donde se iban tirando las medidas. Estos atentados sin ejemplo ofenden lo más vivo de nuestros sentimientos. ${ }^{43}$

Los indígenas consideraban "imposible" que hubiera "alguna parte de terreno baldio o mostrenco", porque "el repartimiento de las tierras del sitio donde se halla fundado este pueblo data desde la fundación del mismo edificio indestructible". Además, con el transcurso del tiempo las fracciones originales se habian ido multiplicando, de tal forma que estaban convertidas en minúsculas parcelas de tres o cuatro surcos cada una. Así, las pretensiones de los fraccionadores y del agrimensor carecían por completo de realismo y no eran más que un intento de despojo. Además de las cinco firmas que acompañaban al escrito, se incluyó "un padrón de los indígenas que entran a la defensa de los terrenos que les andan midiendo del sitio, para quitárselos los mismos indígenas contrarios del mismo pueblo de Jesús María". En total, fueron 350 los comuneros que se sumaron a esta protesta. ${ }^{44}$

No sabemos cuál fue el desenlace de este pleito. A juzgar por las eviden-

\footnotetext{
41 Toda esta relación en AGEA-PJ (Civil), 1883, p. 17.

42 lbid.

43 Ibid.

4 Ibid. El estilo de todos estos escritos es muy vivo, casi visceral, prueba de que la comunidad respondió a la agresión con la mayor rapidez y de que no tenía tiempo para dispensar cuidados de forma a sus documentos o para contratar los servicios de un plumífero.
} 
cias documentales de que disponemos, que en este punto no ofrecen una conclusión definitiva, parece que el deslinde no tuvo mayor éxito. Hay que tener en cuenta que la comunidad reaccionó rápidamente $y$ en forma mayoritaria, denunciando a los ambiciosos y tratando de conservar indiviso su más preciado patrimonio. El hecho de que fueran los indígenas mismos los que en esta ocasión quisieran hacer un negocio privado con los bienes del pueblo no debe llamar excesivamente la atención. Es cierto que las más de las veces los ataques contra los indios tenían su origen en grupos criollos o españoles, pero también es cierto que, en alianza con elementos extraños o por su propia iniciativa, los mismo indígenas arremetían frecuentemente contra los bienes de los pueblos. ${ }^{45} \mathrm{~A}$ los tradicionales peligros, así, había que agregar ahora la amenza inminente de un "cisma". Y a este último respecto hay que insistir en el lenguaje casi de guerra santa que emplean los comuneros en sus diversos escritos de defensa. Hablan del pueblo como de un "edificio indestructible" y de los ambiciosos como de unos "conspiradores". Imposible eludir el sentido radical de estas expresiones: la comunidad se sentía amenazada en su integridad misma y reaccionaba violentamente.

\section{La lucha por el agua.}

Las tribuiaciones del pueblo de indios de Jesús María no se limitaban a la defensa de sus tierras: también el agua, que era escasa y resuitaba vital en todas las labores agrícolas, fue motivo de enconadas disputas. El fundo legal del pueblo estaba atravesado por un pequeño río que llevaba agua todo el año y con el cual se daba riego a las huertas y parcelas. Las cosas transcurrieron normalmente, sin dificultades mayores, a lo largo de todo el siglo XVIII. A principios del siglo XIX, sin embargo, el dueño de la hacienda de Las Trojes, don Felipe Pérez y Terán, decidió construir una presa en el curso del río. Francisco Suárez, alcalde mayor del pueblo, en un acto quizá de buena fe pero que nunca le perdonarían sus hermanos, cedió a Terán la servidumbre real de las aguas que corrían por el río y daban riego a sus tierras. ${ }^{46}$ Levantada la presa, se encontró que algunas de sus acequias atravesaban terrenos pertenecientes a los indígenas jesusmarianos. Así, desde el punto de vista de la comunidad el problema era doble, pues por un lado el cauce del río estaba sensiblemente disminuido (por culpa de la cortina, que interrumpía el flujo de aguas) y por el otro la construcción de los canales se había traducido en una disminución de sus ya de por sí minúsculos terrenos. Las dificultades se allanaron cuando Pérez y Terán convino en que los indígenas afectados por el trazo de las acequias pudieran hacer uso del agua que por ellas corría en el riego de sus terrenos. Así, aunque se habían perdido algunos surcos, se obtenía el derecho de usufructuar gratuitamente un sistema de riego. ${ }^{47}$

45 Como punto de comparaćión.puede pensarse en el Querétaro colonial, donde "Ios ataques a las tierras de los indios adoptaban diversas formas y cada una tenia como resultado un debilitamiento de la propiedad comunal. Los indios usurpaban tierras de indios... Los caciques eran en cierta forma responsables por la pérdida de tierras. Por su negligencia o por colusión traspasaban muchas tierras a los españoles. (Sin embargo) los ataques más eficaces a las tierras de los indios provenían de los españoles. no de los indios..." (Véase: John C. Super, La vida en Querétaro durante la Colonia, 1531 -1810, México, Fondo de Cultura Económica, 1983, p. 189 190.)

46 Una constancia de esta cesión en AGEA-PN. Not. Tranquilino Mercado, 1891-1892, p. 109, 149-150.

47 Los dueños de la hacienda de Las Trojes siempre alegaron que los derechos de propiedad que representaban sobre la prensa de Jesús María eran inobjetables. Dońa Refugio Díaz y Porllo, empero, se vio obligada a ser puntillosa en extremo: "he tenido derecho de propiedad en esa presa, es decir. en la fábrica a modo de pared o muralla de piedra con que se ataja o detiene el río". Véase: AGEA-PJ (Civil), 1893. p. 336 (subrayado nuestro). 
En 1835. don Jacinto Terán intentó quitar el uso del agua a los comuneros, pero éstos se resistieron y lograron llegar finalmente a un acuerdo. ${ }^{48}$ Tiempo después, en diciembre de 1869, los indígenas quisieron hacer un uso más extenso de las aguas, para lo cual, por medio del Ayuntamiento, se dirigieron al Congreso estatal pidiendo que se les concediera el derecho de regadío para algunos terrenos pertenecientes al fundo del pueblo. La Comisión de Gobernación. a la que fue turnado el asunto, vio con simpatía la causa de los indígenas; sin embargo, el ocurso:

no contiene datos de ningún género para fundar alguna resolución definitiva, pues únicamente consta de algunos alegatos en favor de la conveniencia pública, haciendo saber que hace algunos años el vecindario de Jesús María habia sido privado del derecho del agua de la presa por el dueño de ella y que por este mal ha refluído poderosamente sobre multitud de familias que antes disfrutaban del derecho de regar sus terrenos; pero en ninguna parte se encuentra en virtud de qué derecho han sido privados del beneficio del agua, ni la razón por que un atentado de tanta magnitud contra las franquicias de un pueblo ha podido pasar desapercibido en medio de las garantías que las leyes otorgan a los municipios. $^{49}$

Los legisladores se preguntaban: "¿cómo y qué razones de justicia han podido obrar en el ánimo del propietario para despojar a un pueblo de un derecho tan sagrado a la faz del mundo. y en un estado donde se otorgan garantías a la propiedad y donde existen los tribunales necesarios para hacer justicia a los que la necesitan?" También liamaba la atención de los enjundiosos diputados el que los vecinos de Jesús María hubieran guardado silencio acerca "de un negocio que tan altamente concierne a los elementos de vitalidad de un municipio que vive del cultivo de las legumbres". Se trataba sin duda de "un despojo violento y criminal, a cuyo autor debiera tratarse con el rigor de las leyes, exigiéndole la responsabilidad de sus actos de barbarie". Sin embargo, los indios no señalaban con claridad si habían venido disfrutando de las aguas de la presa por derecho propio o por gracia; en el primer caso "habría que instaurar un juicio de despojo". y en el segundo habría que "solicitar una expropiación a trueque de utilidad pública". Con este ánimo se resolvió que la petición fuera devuelta a los jesusmarianos. "para que expresen con claridad si el beneficio del agua de la presa lo han disfrutado por gracia del propietario o en virtud de un derecho legítimo". Asimismo. se decidió comunicar el acuerdo al jefe del ejecutivo para que a los comuneros "se les haga pronta y cumplida justicia, previa justificación de sus derechos". 50

El asunto, pese a que la opinión de los diputados era tan abiertamente favorable a los indígenas, no pudo prosperar. Al parecer, la comunidad no hizo caso de la recomendación que se le giró y se olvidó de volver a plantear el asunto. Quizá el problema haya consistido en que los indios recibieron tan

48 El 20 de octubre de 1835, 193 naturales de Jesús María confirieron un poder a Esteban Marcial para que "principie, siga y concluya todos los pleitos, causas o negocios, civiles y criminales, que al presente están pendientes o en lo sucesivo se les ofrezcan con la casa de don Jacinto Terán y testamentaría de su finado padre, don Felipe Terán..." Fue seguramente Marcial quien logró llegar a un acuerdo con el dueño de Las Trojes. Véase: AHEA-FPN. Not. José María Medina, 1835, s.n., p. 111-114.

49 La Comisión de Gobernación estaba integrada por Agustín R. González y Juan G. Alcázar. Su resolución en AGEA-Ramo del Poder Legislativo (en lo sucesivo PL). p. 202. 668. 1.

so lbid. 
sólo una nota escueta y formal, que no reflejaba en absoluto cuál era el sentir real de la Cámara en torno al asunto. En este caso la comunidad pudo interpretar que su solicitud no era vista con simpatía y que se pretendía involucrarla en un trámite burocrático, fatigoso e inútil. Así, se prefirió romper la comunicación con los diputados. También es posible que el propietario de la presa, alarmado por el giro que estaban tomando los acontecimientos, haya procurado un arreglo directo con los comuneros, a cambio de que estos desistieran del trámite emprendido. Pero en fin, el hecho es que no hubo a la postre resolución positiva hacia la demanda de los indígenas.

En 1890 doña Refugio Diaz y Portillo vendió sus haciendas de Los Cuartos, Las Trojes y Chichimeco a Jesús Díaz Infante, quien negó a los indios el tradicional uso de las aguas. Como siempre, la comunidad recurrió para su defensa a medios legales. El 27 de agosto de 1890, cuarenta labradores vecinos de Jesús María y dueños de terrenos atravesados por las acequias de la hacienda de Las Trojes, otorgaron un poder al licenciado José N. Romero, para que "los represente en cuantos asuntos se relacionan con la propiedad y posesión de los repetidos terrenos" 51 Eł problema era delicado ya que Diaz Infante, en una maniobra claramente especulativa, se habia valido del derecho de los indígenas al uso de las aguas para declararse en suspensión de pagos, alegando "irregularidades" en la entrega de las haciendas. Los indígenas, asi, estaban siendo utilizados como peones de sacrificio, ya que ni Díaz Infante ni Díaz y Portillo pretendían legitimar su derecho al uso de las aguas, pero ambos querian capitalizar su lucha en provecho propio.

La situación se complicó cuando Díaz Infante obtuvo el amparo de la autoridad judicial $y$ dejó a sus acreedores sin dinero y sin posibilidades de recuperar en el plazo inmediato sus terrenos. Los indios continuaron por su cuenta con la defensa de sus derechos. El 23 de septiembre de 1892 confirieron un poder al licenciado Cesáreo L. González:

para que... sostenga los derechos que les asisten en el uso de las aguas que de la presa del río de Jesús María se conducen por regaderas construidas sobre propiedades de los que llevan la voz para terrenos de la hacienda de Los Pocitos (fracción de Las Trojes), haciendo valer en este litis con toda su extensión y fuerza necesarios todos los derechos que legalmente les corresponde... ${ }^{52}$

Por otra parte, el licenciado Onofre Valadez, como apoderado de la señorita Díaz y Portillo, estaba promoviendo ciertas diligencias que tenía por fin "dar posesión judicial a Jesús Díaz Infante de toda el agua que contiene la presa llamada de Jesús María..."53 Naturalmente, Díaz y Portillo trataba de defender sus intereses, pues si lograba su cometido, Díaz Infante se vería en la inaplazable necesidad de pagar o de devolver las fincas.

El apoderado de los indígenas impugnó el procedimiento, alegando que en su concepto la posesión judicial solicitada tenía por objeto:

interrumpir y aún quitar la quieta y pacífica posesión que sobre la misma agua han tenido y disfrutado mis representados desde que tales obras fueron construidas, $y$ antes, de tiempo inmemorial, cuando libremente corría el agua por el río público y de uso común que surte la presa mencionada.

51 AGEA-PN. Not. Taide López del Castillo, 1890-1892, s.n., p. 21-24.

52 AGEA-PN, Not. Fernando Cruz, 1892, s.n., p. 20-22.

53 AGEA-PJ, (Civil), 1892, p. 142. 
El licenciado González decía que los indios de Jesús María tenían derecho al uso de las aguas "como ribereños del río" y "por otro título más, cual es de prescripción". Por ello, las pretensiones de Díaz y Portillo constituían "una amenaza grave e ilegal que producirían en definitiva el despojo de un derecho legítimamente adquirido". González concluía demandando por la vía sumaria "la retención de la posesión" ${ }^{54}$ El juez de lo civil $y$ de hacienda, José Villa Gordoa, admitió la demanda, obtuvo la información que el caso requería y dictó sentencia el 30 de noviembre de 1892. El fallo negó el interdicto de retención solicitado, ya que a pesar de estar "fincada la posesión pacífica $y$ continua por más de un año y un día" (primera condición), no había "el acto preparatorio que tienda directamente a la usurpación violenta de esa posesión, o cuando menos la amenaza grave de ese mismo despojo o usurpación" (segunda condición). ${ }^{55}$

Por otro lado, las diligencias promovidas por Refugio Díaz y Portillo, tendientes a dar posesión judicial de la hacienda de Las Trojes y de la presa de Jesús María a Jesús Díaz Infante, siguieron su propio curso. El Supremo Tribunal de Justicia del Estado, mediante sentencia del 29 de agosto de 1892. determinó que era de otorgarse la posesión solicitada. Poco después, con la intención de acelerar los trámites, el apoderado legal de la señora Díaz y Portillo pedía al juez de lo civil que se diese a Díaz Infante la posesión efectiva de la presa. De nuevo fueron atendidos los reclamos de la señora, y el 10 de enero de 1893 se verificó una ceremonia formal de adjudicación de derechos sobre la disputada presa, "dejando a salvo los derechos de algunos indígenas de Jesús Maria que protestaron en el acto de la posesión". ${ }^{56}$ Este conjunto de circunstancias ponían a Jesús Díaz Infante en la inaplazable obligación de satisfacer sus obligaciones pecuniarias con la señora Díaz y Portillo $y$, al parecer, eso era lo que a base de tanto enredo legal estaba procurando evitar. Díaz Infante quería continuar con el aprovechamiento de las fincas rústicas, pero siempre y cuando ello no le significara una responsabilidad pecuniaria. Así, no puede extrañar que este ladino agricultor haya protestado la providencia del juez en virtud de la cual se le daba posesión de la presa. Su querella fue escuchada, y el 12 de junio de 1894 el Supremo Tribunal pronunció una sentencia revocando la del 16 de enero de 1894 , es decir, dejando sin efecto el acto de la posesión judicial. ${ }^{57}$

El problema era dificil para doña Refugio, pero más difícil era aún a los ojos de los indígenas jesusmarianos. Estos conocían ya la rapacidad de Díaz Infante y eran por tanto los primeros interesados en que devolviera las fincas a su primitiva propietaria. Sus acciones, sin embargo, se sucedian con atropellamiento, pareciendo entorpecer el logro de sus propios objetivos y perjudicando igualmente el manejo legal del asunto por parte de la señora Díaz y Portillo. Todo indicaba la necesidad de que los indios y doña Refugio arribaran a un acuerdo, pudiendo de esta manera presentar un frente único ante Díaz Infante. La comunidad estaba aferrada a sus recelos, y no en balde. pues eran ya muchos los abusos de que había sido víctima. Sin embargo. convinieron en maniobrar legalmente junto a la señora Díaz y Portillo. Desde los primeros días de septiembre de 1892, cuarenta agricultores "dueños de los terrenos que están a lindes de las acequias que parten de la presa de Je-

\footnotetext{
54 Ibid.

55 Ibid. Al año siguiente, el licenciado González realizaría nuevos trámites oponiéndose a que se diera posesión de las aguas de la presa a Jesús Diaz Infante. (Véase: AGEA-PJ (Civil), 1893. p. 212.1

So AGEA-PJ (Civill. 1892.p. 142

57 Ibid.
} 
sús María y llegan al rancho conocido por Los Pocitos", vendieron a doña Refugio sus derechos sobre el agua de la citada presa, en cantidad de 2500 pesos. ${ }^{58} \mathrm{Tal}$ parecia que los indígenas daban su herencia a cambio de un plato de lentejas. Empero, habían tenido buen cuidado de "asegurar los derechos" que otorgaban. La señorita Díaz y Portillo adquirió ante notario un compromiso en los siguientes términos:

inmediatamente que recobre o se rehaga de las fincas de campo nominadas Los Cuartos. Las Trojes y Chichimeco, que actualmente pertenecen a Jesús Díaz Infante, volverán (los indios) a usar del agua en el riego de sus terrenos, como puedan y hasta donde puedan, y en este caso se la distribuirán en usufructo $y$ en proporción todos los indicados dueños (de terrenos)... (pero) en el remoto caso de que Jesús Díaz Infante se quede con dichas fincas, la señorita Díaz y Portillo indemnizará a los mencionados dueños con la cantidad de cinco mil pesos, cantidad que se distribuirá entre los mismos mencionados dueños en proporción al tamaño de sus terrenos... ${ }^{59}$

El objetivo de todos estos malabarismos legales, entonces, era claro: situar a doña Refugio en una posición desde la que pudiera recuperar sus fincas. Los indios no renunciaban a sus derechos, sino que aceptaban ofrecer un frente único contra las ambiciones de Díaz Infante. Sin embargo, como ya lo vimos en el párrafo anterior, la buena voluntad de los indígenas se vio obstruida por un celo quizá excesivo, que los llevó a objetar la posesión fincada a principios de 1893 a favor de Díaz Infante.

Tan enojoso y prolongado pleito tuvo finalmente un desenlace justiciero: Jesús Díaz Infante se vio obligado, por sentencia judicial, a devolver las haciendas de Las Trojes, Los Cuartos y Chichimeco a su primitiva dueña, doña Refugio Díaz y Portillo. Al poco tiempo, la señora vendía el rancho de Los Pocitos, fracción de Las Trojes, al licenciado Heraclio Zepeda Garibay. ${ }^{60}$ Este, violentando los acuerdos habidos anteriormente entre los indigenas y los propietarios de Las Trojes quiso monopolizar el uso de las aguas provenientes de la presa y suspender de tajo toda concesión. La situación se tornó crítica para los comuneros, en especial para aquéllos cuyas parcelas habian hecho uso desde siempre de las aguas de la presa y del río. llegándose el punto en que empezaron a aprovechar las acequias y canales contra la voluntad del dueño de Las Trojes. Heraclio Zepeda Garibay, por su parte, promovió diversas diligencias legales tendientes a ratificar y ampliar sus derechos sobre el agua de la presa. Cien vecinos de Jesús Maria respondieron a estas maniobras el 21 de octubre de 1907 otorgando un poder al licenciado Magdaleno Díaz Véliz.

para que... conteste las demandas y las promueva en defensa de sus bienes. derechos y servidumbres de aguas que tienen en este municipio... y en especial lo autorizan para que se apersone en los juicios que promuevan o sean promovidos por el licenciado Heraclio Zepeda Garibay sobre reclamación de las aguas del río San Pedro y presa de Jesús María... ${ }^{\text {B1 }}$

Estas dificultades eran en el fondo la actualización de un problema secular, originado en los albores del siglo $\mathrm{xIX}$, cuando el alcalde mayor del pueblo

58 AGEA-PN, Not. Tranquilino Mercado, 1891-1892, p. 110, 150-151.

59 AGEA-PN Not. Tranquilino Mercado, 1891 -1892, p. 109, 149-150

- El contrato compraventa en AGEA-PN, Not. Mariano Ramos, 1900, p. 6, 7-12

61 AGEA-PN, Not. Tranquilino Mercado, 1907, p. 41, 82-85. 
fincó una servidumbre de aguas a favor de Felipe Pérez y Terán. El agua era escasa, aunque durante muchos años corrió libremente por el cauce del río, de tal manera que todos los pequeños propietarios de terrenos aledaños podian hacer uso de ella. La construcción de la presa alteró sustancialmente el panorama, al constituirse un hacendado en el monopolizador de las aguas del río. De ahí en adelante, los indígenas tendrían acceso a ciertas acequias, pero ello no dejaba de tener cierto aire de favor gratuito. Los sucesivos propietarios de la hacienda de Las Trojes siempre pensaron que el uso de la presa les pertenecía en exclusiva y que la ayuda que se daba a los indios para sus riesgos no se traducía de manera alguna en derechos de propiedad. Doña Refugio Díaz y Portillo interpretaba fielmente esta mentalidad cuando hablaba de los indígenas "que sin derecho alguno pretenden hacer uso de las aguas que corren por las acequias de la presa". En realidad, los comuneros perdieron la batalla por el agua desde el momento en que aceptaron fincar la servidumbre. Todo to demás no fue sino una sucesión de intentonas más o menos afortunadas de recuperar terreno, de paliar los efectos de aquella desastrosa cesión.

\section{Conclusión}

Una primera cuestión que nos interesa aclarar en estos momentos es la relativa al régimen de tenencia de la tierra imperante en el pueblo de Jesús María: ¿propiedad comunal, propiedad privada o una combinación de ambas? La legislación colonial sancionó y protegió el régimen de propiedad colonial, básicamente con la intención de resguardar a los pueblos de indios de las embestidas de los hacendados criollos. Inclusive, para evitar la concentración del vital recurso, en muchas comunidades las tierras eran periódicamente redistribuidas. Sin embargo, sobre las parcelas familiares, el derecho de los indios era tan sólo de uso y no de posesión plena. ${ }^{62}$ Además, en cada caso particular la legislación tuvo que sufrir adaptaciones. En Jesús María encontramos que el derecho de posesión de las pequeñas parcelas y su libre usufructo eran prácticas ampliamente extendidas, y que nunca se recurrió a la en otras partes extendida costumbre de redistribuir los predios. Esta primacía absoluta de la pequeña propiedad individual, aunque con limitaciones, se explica básicamente por la modesta extensión de las tierras con que fue dotada la comunidad. Las treinta y dos parcelas originales, ya de por sí estrechas, fueron subdividiéndose conforme transcurrió el tiempo y la población se multiplicó. hasta convertirse en más de quinientos pequeños reductos, con una superficie tan modesta que a veces se tenía que medir en surcos.

De esta manera, la guerra de Independencia, con su secuela de legislación libreral y antipatrimonialista, vino simplemente a sancionar una situación que ya tenía vigencia en los hechos. Las Cortes de Cádiz habían ya decretado en 1813 la reducción a propiedad privada de todas las tierras de los pueblos. Después, en el Congreso Constituyente muchos diputados se mostraron hostiles al régimen comunitario, aunque finalmente no se legisló nada sobre el particular. Por su parte, algunas diputaciones estatales se comportaron como fieles intérpretes de la ortodoxia liberal, postulando un régimen único de propiedad privada ${ }^{83}$ En particular, el gobierno zacatecano de Fran-

62 Sobre algunas de las peculiaridades de los derechos de propiedad comunal sobre la tierra pueden consultarse, entre otros textos, los siguientes: Wistano Luis Orozco, Los ejidos de los pueblos. México. Ediciones El Caballito, 1975. y Guadalupe Rivera Marín de Iturbe. La propiedad territorialen México, 1301-1810. México. Siglo XXI. 1983. p. 216-227

63 Algunos de estos señalamientos se encuentran en Charles A. Hate, El liberalismo mexica. no en la época de Mora, 1821 - 1853, México, Siglo XXI, 1972.p. 232. 
cisco García Salinas anuló la existencia legal de las tierras de comunidad y pretendió obligar a los indígenas a registrar sus lotes en calidad de predios privados. Finalmente, las muy conocidas leyes de desamortización y nacionalización negaron el derecho de las corporaciones a poseer bienes raíces.

Esta avalancha de liberalismo llegó finalmente a Aguascalientes, donde el gobernador Jesús Terán decretó, en agosto de 1856, el fraccionamiento de tres sitios de ganado mayor ubicados en la Sierra Fría y pertenecientes al pueblo de Jesús María. Este decreto no afectaba las tierras de la parte de abajo, las que se poseían desde 1699. en las que ya de hecho privaba en forma absoluta la posesión individual. Una revisión superficial de los protocolos notariales correspondientes al municipio jesusmariano y fechados en la década de 1850, indica claramente que los indios consideraban propias las parcelas y que comerciaban con ellas en forma completamente libre. ${ }^{64}$ Lo que no está claro, sin embargo, es el momento en que los indigenas registraron sus tierras. Es posible que hayan esperado hasta 1906. cuando con motivo de la Ley de Revalorización de la Propiedad Rústica se vieron obligados a inscribirse en los padrones oficiales.

Por otra parte, conviene señalar que durante el siglo xIX la existencia del pueblo de indios de Jesús María gira en buena parte en torno a la defensa de sus tierras y de sus derechos sobre las aguas. Esta lucha constituye una especie de clave íntima en la pequeña reconstrucción histórica que hemos intentado. La comunidad defendió sus recursos contra la voracidad de los hacendados vecinos, contra las necesidades apremiantes de otros pueblos hermanos, e incluso contra las iniciativas de despojo nacidas en el seno mismo de la comunidad. Ahora bien, no deja de llamar la atención el que los indígenas hayan encaminado siempre sus defensa por los cauces legales. Hasta donde sabemos, los de Jesús María no acostumbraban proceder por propia iniciativa, menospreciando las vías de la justicia establecida. Esta sumisión es sin duda un resabio de la época colonial, cuando con alguna frecuencia los tribunales reales fallaban en favor de los indios, así esto causara insatisfacción en criollos o españoles. ${ }^{65} Y$. según se ha visto en este trabajo. los indios conservaban la fe en los conductos oficiales. Esa fe, por lo demás, era con cierta frecuencia bien correspondida, lo que muestra que durante el porfiriato no era la palabra del caudillo y sus incondicionales la única que tenía vigencia, y que, por lo menos en ocasiones, los tribunales correspondían con criterios de estricta justicia.

64 Protocolos de los notarios Antonio Rodríguez Leal, Jesús Ramírez, Esteban Marcial. José Antonio Hernández, Francisco Salado y Mariano Martínez, en el Archivo Histórico del Estado de Aguascalientes.

65 Para fines de la época colonial era ya una costumbre que los indígenas defendieran sus derechos ante los tribunales españoles. En 188, un total de 55 pueblos tenian en curso pleitos y reclamaciones. (Véase: Ramón Maria Serrera, Guadalajara Ganadera, España, Escuela de Estudios Hispanoamericanos de Sevilla, 1977, p. 336.) 